International Journal of Linguistics, Literature and Translation

ISSN: 2617-0299 (Online); ISSN: 2708-0099 (Print)

DOI: $10.32996 / \mathrm{ijllt}$

Journal Homepage: www.al-kindipublisher.com/index.php/ijltt

\title{
Evaluation of Remote Teaching during the COVID-19 Pandemic: The Case of Higher Education in Morocco
}

\author{
Dr. Rym Asserraji \\ Assistant Professor at Moulay Ismail University, Faculty of Sciences, Meknes. Morocco \\ $\square$ Corresponding Author: Dr. Rym Asserraji, E-mail: r.asserraji@umi.ac.ma
}

\section{ARTICLE INFORMATION \\ Received: 08 September 2021 \\ Accepted: 14 October 2021 \\ Published: 30 November 2021 \\ DOI: 10.32996/ijlt.2021.4.11.3}

\section{KEYWORDS}

Remote teaching challenges, higher education, covid19 pandemic

\section{ABSTRACT}

The deadly and infectious disease Corona Virus also known as Covid19, has deeply shaken the global economy. This tragedy has also affected the education sector, and this fear is likely to reverberate across the education sector universally. Various schools, colleges, and universities have discontinued in-person teaching. According to the assessment of the researchers, it is uncertain to get back to normal teaching anytime soon. Hence, social distancing is dominant at this stage, a fact that will have negative outcomes on learning opportunities. As it is stated by Stanley (2019:8), Educational units are struggling to find options to deal with this challenging situation. These circumstances make us realize that scenario planning is an urgent need for academic institutions. Therefore, the purpose of this article is to shed light on the challenges of remote teaching during the Covid19 pandemic on teachers at the university level and to try to figure out the possible resolutions and recommendations to develop distance teaching. A questionnaire has been designed as the major data collection instrument to carry out the investigation. The respondents are university professors affiliated with public and private universities in Morocco. Concerning the findings of the study, the respondents believe that remote teaching is extremely challenging due to a variety of factors and it is not effective at all.

\section{Introduction}

The calamity of COVID-19 has exposed the flaws and imperfections of poor and undeveloped education systems in many countries. Certainly, COVID-19 shut down all doors of schools and universities all over the world, but the effect of this closure varied across countries. For example, in countries with developed educational systems, such as the UK, USA, UAE, Saudi Arabia, Italy, and Germany, the process of teaching and learning was abruptly discontinued before moving to E-learning and distance teaching. This shift was promising in the sense that teachers, students, schools, and universities in these contexts were well-equipped to face it. Nonetheless, in countries with poor and undeveloped educational systems, like Morocco, shutting the doors of schools and universities has directed to complete stoppage of the teaching and learning process for all levels of education including the highest level. In a paper presented by Mehrotra et al. 2001), remote education was described not as a future option for higher education institutions, but as a reality. Later, Hanover's research (2011:1) indicated the significant increase in the number of higher education institutions in the world that grant distance education programs. Stanley (2019:8) states that remote teaching "occurs when teachers are brought into the classroom virtually, using videoconferencing technology...". In other words, remote teaching means teaching from a distance when teachers and students converse online instead of in the classroom. As a result, the main purpose of this article is to try to define the challenges that Moroccan university professors have encountered during the lockdown caused by the COVID-19 pandemic and to try to find out the possible solutions and recommendations to adopt them.

\section{Literature Review}

Stanley (2019:8) clarifies that remote teaching prevails the moment when both teachers and students are joined together in a virtual classroom, utilizing video conferencing technology. The requirement of remote teaching has improved as an answer to the interest and high enrollment numbers for online language learning courses. Compton (2009:3) believes that because of the increase in internet services and the growth of computers at home and in education institutions, online language learning has progressively

Copyright: (C) 2021 the Author(s). This article is an open access article distributed under the terms and conditions of the Creative Commons Attribution (CC-BY) 4.0 license (https://creativecommons.org/licenses/by/4.0/). Published by Al-Kindi Centre for Research and Development, London, United Kingdom. 
advanced in fame in the last decade. In some papers, the concepts of distance or online learning and remote teaching are used interchangeably, ignoring the fundamental distinction between them in terms of the role of the teacher and learner.

In remote teaching, the teacher argues his major role in making decisions about course content, mode and rapidity of delivery, and evaluation, whereas in remote learning learners are more independent in making decisions with a shrinking function for teachers. Remote teaching is more demanding than classroom teaching as it necessitates more and different skills and competencies. Teaching online differs from classroom teaching in all aspects including materials preparation, methods of instruction and delivery, assessment in addition to teacher and learner roles. Therefore, Online teachers ought to develop technological, pedagogical, and evaluation skills to be capable of performing their new tasks and responsibilities (Compton, 2009; Whyte \& Gijse, 2016).

\section{Methodology}

Since March 16th, 2020, the Moroccan authorities have decided to suspend face-to-face courses in public and private schools and universities in order to comply with the containment measures related to the Covid-19 health crisis. In addition, several measures have been taken to ensure the continuity of distance teaching by supporting university professors to get accustomed to this new teaching environment. Hence, the major aim of this paper is to investigate teachers' perceptions towards distance teaching during the Covid19 pandemic in higher education.

The questionnaire has been designed as the major data collection instrument. As for the respondents, they are Moroccan university professors who teach in private and public institutions and universities around Morocco, such as Fez, Meknes, Rabat, and Kenitra. Concerning the questions mentioned in the questionnaire, they are divided into four major categories namely, information on respondents' academic path, their encountered challenges regarding distance teaching continuity, their self-organization for distance teaching, and their evaluation of the used teaching platform.

\section{Results}

\subsection{Background Information}

As far as the findings of this study are concerned, they have been classified into a number of sections. The first one deals with an analysis of my respondents' background information. It discusses gender and the institutions that they are affiliated with. Concerning the second section, it tackles some information on their academic path, such as the institution sector as well as their teaching experiences. As for the third one, it is about their encountered challenges with regard to remote teaching as well as the way they have delivered online courses during the confinement period. As for the section of self-organization for remote teaching, the questions are centered on the time allotted to remote teaching per day, institution accompaniment during the remote teaching process, their self-organization during remote teaching activities, in addition to the online teaching support and the kinds of difficulties they have encountered during the remote teaching process. As far as the last section is concerned, it discusses respondents' evaluation of the used teaching platforms. The questions within this section have been centered on the types of video conferencing tools, which have been used by my respondents, the strengths of the educational platform, its contribution to remote teaching continuity, and the use of the institution platform after the confinement period.

\section{Are you? \\ 228nbsp:réponses}

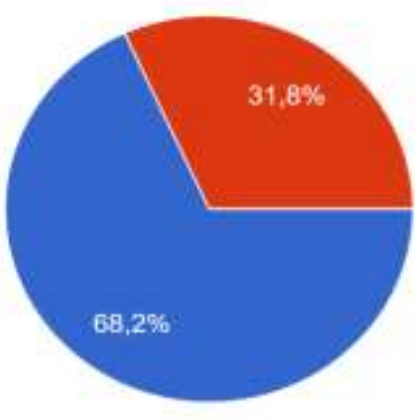

Figure1: Gender

$68,2 \%$ of respondents are males while $31.8 \%$ are females. 
In which institution do you teach?

228nbspjéponses

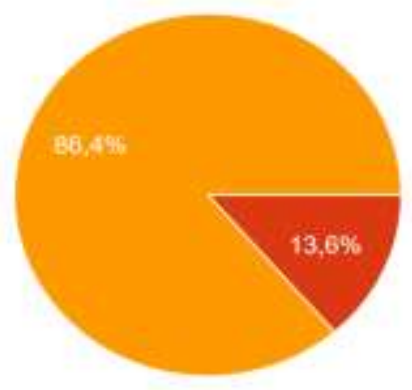

Preparatory classes

Higher school

University

Figure 2: The Institution Affiliation

Most of the respondents are university professors working at the university; whereas, $13,6 \%$ work in higher institutions at the university level.

\subsection{Information on the Academic Path}

In which type of academic institution, do you teach at?

22.nisspreponses

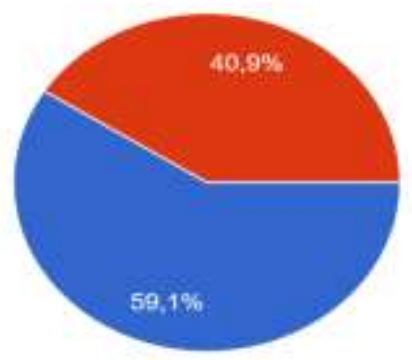

Figure 3: The Institution Sector

Most of them teach in the public sector while $40,9 \%$ in the private one

How long have you been teaching?

228nbspréponses

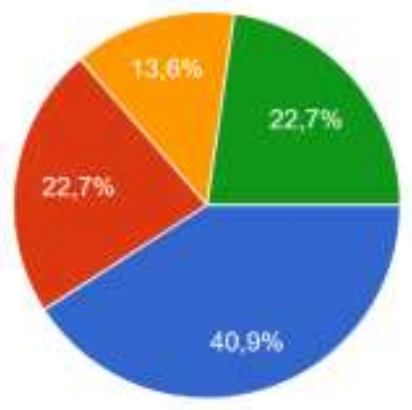

For five years

For 10 years

For 20 years

For more than 25 years

Figure 4: The Teaching Experience 
Apparently, the teaching experience of my respondents varies in terms of experience. Most of the respondents have been teaching for five years $40.9 \%$. Likewise, there is an equality of percentages of two alternatives, meaning that my respondents' teaching experience varies from ten years to twenty years while $13,6 \%$ have been teaching for more than twenty-five years

\subsection{Challenges of distance teaching continuity}

\section{Has your institution ever introduced you to distance teaching even before the pandemic? 228 nbspréponses}

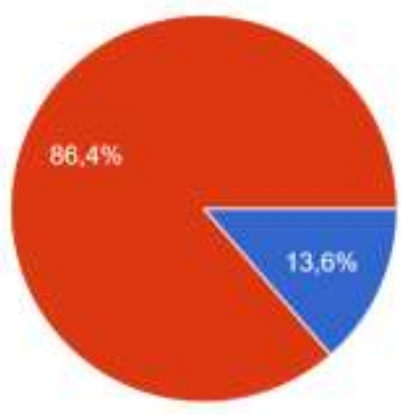

$$
\text { Y Yes }
$$

Figure 5: Introduction to Distance Teaching

$86,4 \%$ argue that they have never been introduced to distance teaching before the pandemic; whereas, $13,6 \%$ opt for yes.

University professors, who teach in the private sector state that they have been provided with a brief training on distance teaching; however, they confirm that they have encountered a number of challenges in distance teaching regardless of their introduction to distance teaching

\section{Following the end of the face-to-face courses, what were your concerns about this? 228nbspreponses}

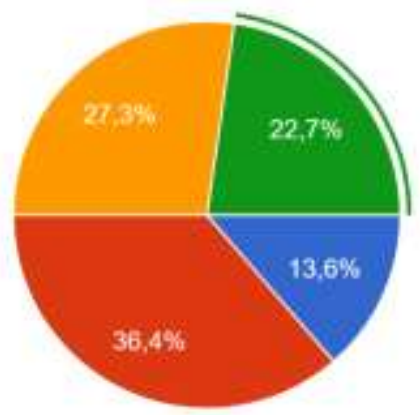

Inability to pursue distance education

The way $\mathrm{lm}$ going to teach

Psychological pressure due to external factors

Other:

Figure 6: Distance Teaching Challenges

Most of them have been anxious about the way they will be teaching since they are not accustomed to the traditional way and most of them confirm that they are not used to technology. Besides, $27.3 \%$ states that their worries $\mathrm{w}$ related to psychological pressure because of external factors; $22,7 \%$ illustrate that there are worried about other factors besides the ones that have been mentioned above, and $13,6 \%$ claim that they are incapable of continuing distance education.

One of them illustrates:

"Distance teaching is extremely challenging to most university professors especially those, who are used to the traditional way of teaching. Besides, delivering courses in the classroom is too effective than distance teaching because there is genuine interaction 
between teachers and students in the classroom while distance teaching is too difficult because of so many various factors namely, wifi connection issues, student's presence, and participation during the online course, and teachers' technology ignorance"

\section{During this period of confinement, did you deliver online courses? \\ 228nbspréponses}

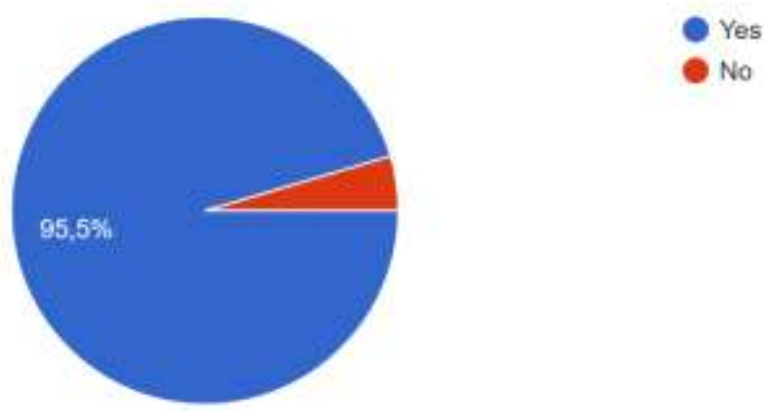

Figure 7: Delivering Online Courses during Confinement Period

Almost all university professors have delivered online courses during the confinement period.

One of my respondents argues:

"Personally speaking, I consider myself as illiterate with regard to technology. However, Thanks to my colleagues' guidance and my students' help that I have learned to deliver my courses effectively. Teaching through academic platforms is s very challenging at first, but with practice, it has become easier and more efficient. However, I am very much fond of the traditional way of teaching"

\section{If so, what means did you use? \\ 228nbspréponses}

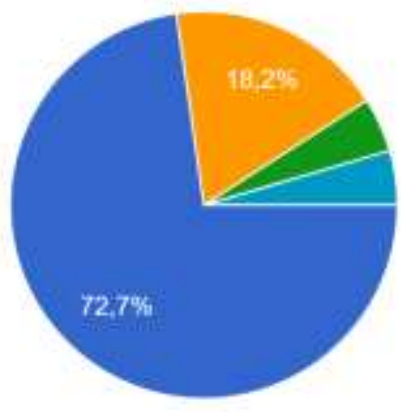

Educational platforms (Microsoft Teams, Google Classroom, Moodle...).

Social networks (Facebook, WhatsApp, Instagram, etc.)

Video conferencing tools (Skype, Zoo...

Website of the establishment

Web page or channel set up by your $\mathrm{P}$...

Email

Moroccan television channels

Other:

Figure 8: The Used Means in Distance Teaching

The majority illustrate that they have taught through educational platforms, such as Microsoft Teams, Google Classroom, and Moodle too while $18.2 \%$ claim that they have used social networks. Besides, others have had access to institutions' websites and only a few have used email.

One of them illustrates:

"I believe that I have been introduced to technology forcefully. I use the educational platform of the institution I am affiliated too, but it is s not enough at all as I had to use the social media applications in addition to my professional email in order to be fully in contact with my engineering students" 


\section{Have you encountered any difficulties during your distance teaching process? \\ 228 nbspréponses}
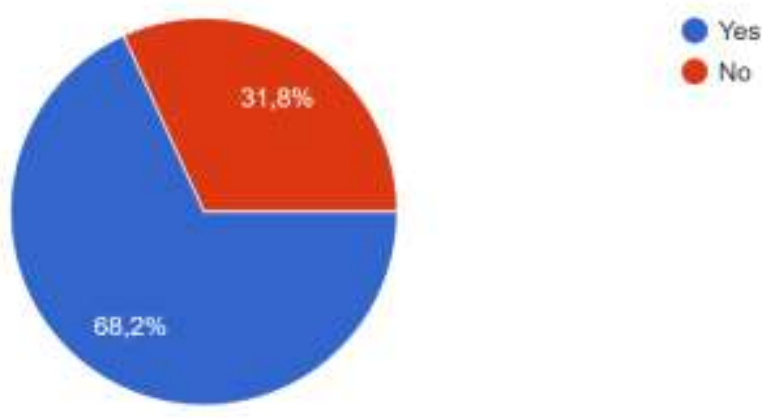

Figure 9: Difficulties in Distance Teaching Process

$68,2 \%$ agree that they have faced various difficulties during the distance teaching process while $31,8 \%$ disagree

\section{If so, what difficulties have you encountered during distance teaching? \\ 228nbspréponses}

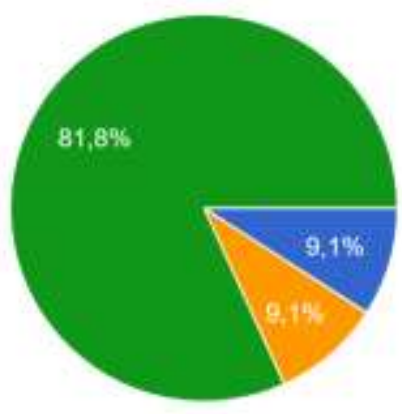

I am not good at using computer applications or smartphones

I don't know how to access the platforms

I do not have the necessary equipment for distance teaching

Other:

Figure10: Encountered Hardships during Distance Teaching Process

The majority believe that they have encountered other various difficulties besides the ones mentioned above. There is also equality of percentages between two alternatives namely, 9,1\% illustrate that they are not good at using computer applications or smartphones and 9,1\% do not have the necessary equipment for distance teaching.

One of my respondents argues:

"I believe that we have suffered from a number of challenges during distance teaching, most of them are related to students' presence during the online class. They do confirm their presence at the beginning of the course, however, when I start calling them by their names to answer the exercises, most of them are absent, and when I mark them absent, they complain by saying that they went to the bathroom or that their connection network went off, a fact which let me say that online courses are incredible" 


\section{Did you provide your students with exams?}

\section{8nbspréponses}

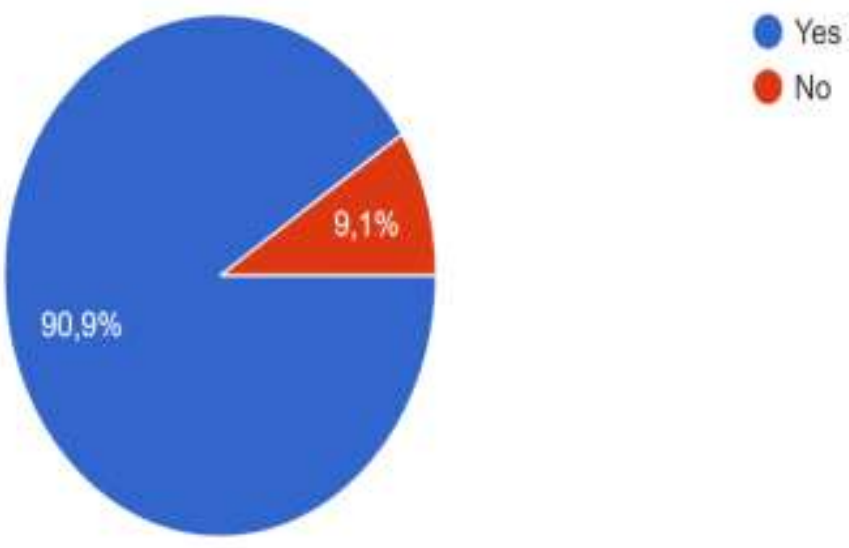

Figure 11: Exams Provision during Covid19 Pandemic

$90.9 \%$ of them argue that exams have been provided to their students; whereas, $9.1 \%$ have said no.

If yes, in which format?

228nbsp;réponses

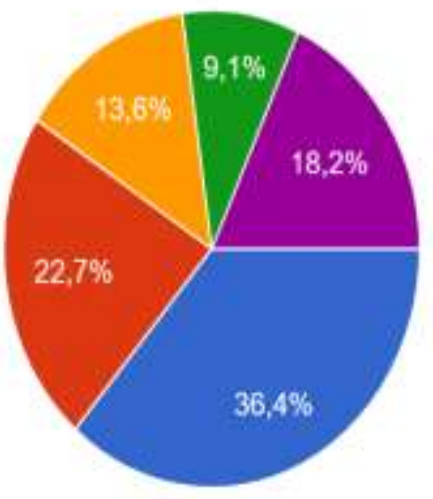

Mini Project

MCQ

Video Conferencing Presentation

Face to face exam

Other:

Figure 12: Exams Format

Apparently, it seems that $36.4 \%$ have provided students with exams in the form of Mini Projects, $22.7 \%$ have opted for multiplechoice question format, $13.6 \%$ have allowed video conferencing presentation format, $18,2 \%$ have chosen other forms for their students, and $9,1 \%$ have selected the option of face to face exams. 
In general, are you satisfied with distance teaching?

228nbspréponses

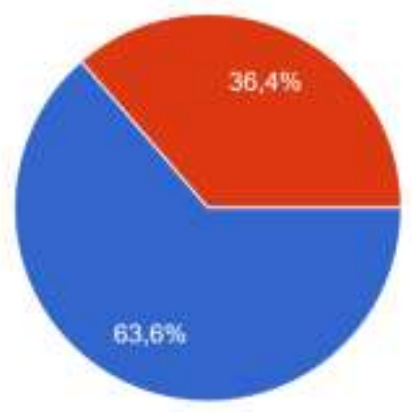

1- No, Not at all

2. Yes, perfectly

Figure13: Satisfaction with Distance Teaching

Most of the respondents believe that they are not satisfied with distance teaching at all; whereas, 36,4\% have claimed that they are satisfied with it.

\subsection{Self-organisation for distance teaching}

On average, how much time do you spend in your distance teaching activities per a day? 22\&nbspréponses

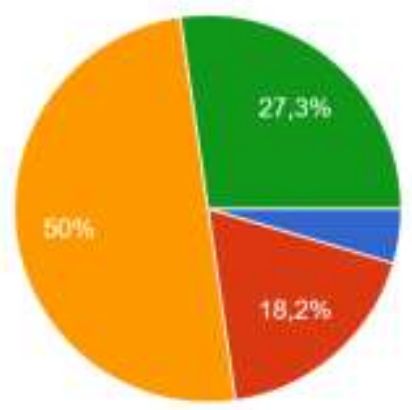

[0-30min]

[30min - 1h30]

[1h30-3h]

More than 3 hours

Figure 14: Time allotted to Distance Teaching per a Day

The majority of respondents believe that they have spent three hours per day in their distance teaching activities, $27.3 \%$ have opted for more than three hours, $18,2 \%$ have chosen one hour and a half, and only $4,5 \%$ have selected thirty minutes.

One of them clarifies:

"According to my humble experience, I can state that distance teaching is incomparable with in-person teaching. The teaching of languages necessitates communication and classroom interaction to be effective; otherwise, the process of teaching and learning will be useless". 


\section{Does a member of your institution accompany you during your teaching process during this period? \\ 228nbspreponses}

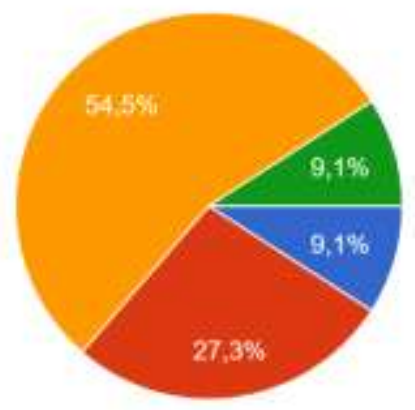

Yes, entirely

Yes, partially

No, I don't need accompaniment

No, they don't have time to help with me

Figure 15: Institution Accompaniment during Distance Teaching Process

$54,5 \%$ claim that they do not need accompaniment while $27,3 \%$ partially need it. There is also equality of percentages between two alternatives, meaning that $9,1 \%$ of them state that their colleagues and friends could not help them since they are busy, and thus they are autonomous while others illustrate that they are provided with assistance.

One of them illustrates the following:

"I teach in a superior engineering school and I can not deny that we are provided with some training sessions on how to deliver courses through Microsoft Team. We are supported by the administration and our software engineering colleagues"

\section{How do you organize yourself in your distance teaching activities?}

228nbspréponses

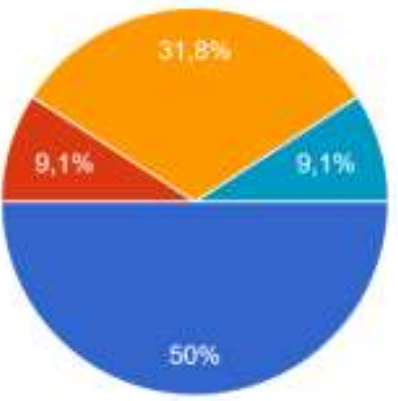

I prepared a space at home dedicated to teaching my courses.

I set myself a daily schedule

I try to stick to the schedule set by my institution.

I regularly check the resources available to teach at home.

I communicate with colleagues who are likely to motivate me to teach.

Other:

Figure 16: Organization during Distance Teaching Activities

The majority points out that space at home has been dedicated to teaching their courses, $31,6 \%$ state that they try to stick to the schedule set by the institution. 9,1\% illustrate that they have set themselves a daily schedule and 9,1\% opt for other types of organizations.

One of them points out the following quotation:

"I have my own office at home. When my distance teaching approaches at home, I go into my office and I lock myself until my distance teaching sessions are finished" 
What is the support used during your online teaching?

228nbspréponses

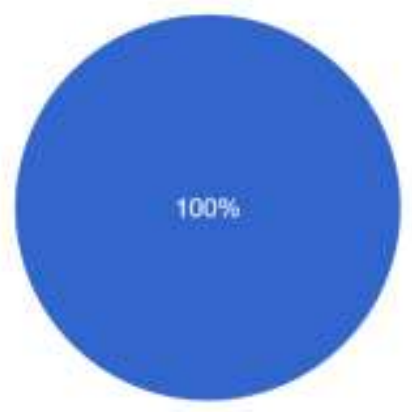

Desktop Computer

Smartphone

Tablet

Smart TV

Other.

Figure 17: Online Teaching Support

All respondents have selected the laptop as the major online teaching support as it is practical and facilitates the distance teaching process to a great extent.

\section{Have you had any problems teaching your courses remotely because of your Internet connection? \\ 228nbspréponses}

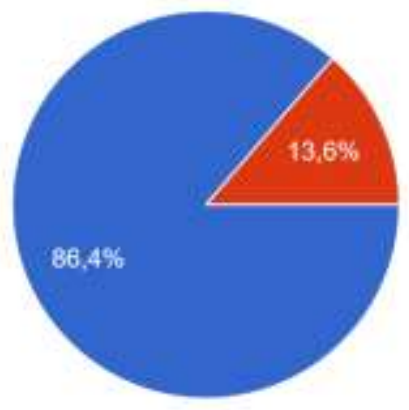

$$
\text { - }{ }^{2} \text { No }
$$

Figure 18: Teaching Problems due to Internet Connection

$86,4 \%$ confirm that they have encountered problems in distance teaching due to internet connections while $13,6 \%$ have had no problems related to it

One of them says:

"The WIFI connection does not facilitate the distance teaching process. It keeps being cut twice to three times during the sessions without forgetting that not all students dispose of it; a fact which blocks the teaching and the learning process" 
If yes, specify the type of difficulty:

228nbspréponses

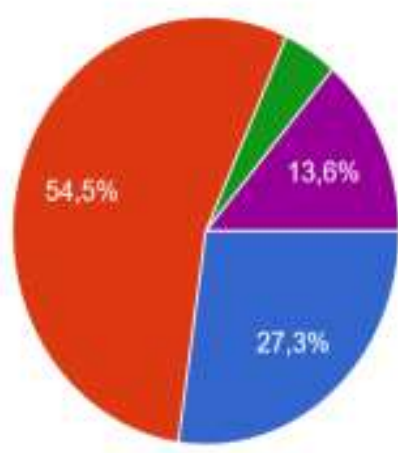

Problem with internet coverage

Low Internet Speed

Sharing the internet with students

Internet Pricing

Other:

Figure19: The Type of Difficulty during Distance Teaching

The majority of respondents have opted for the low internet speed while $27,3 \%$ have difficulties related to internet coverage. $4,6 \%$ complain about the prince of the net and $13,6 \%$ opt for other issues.

\subsection{Evaluation of the used teaching platform}

\section{What is the educational platform that you have used mainly during your teaching? 228 nbspréponses}

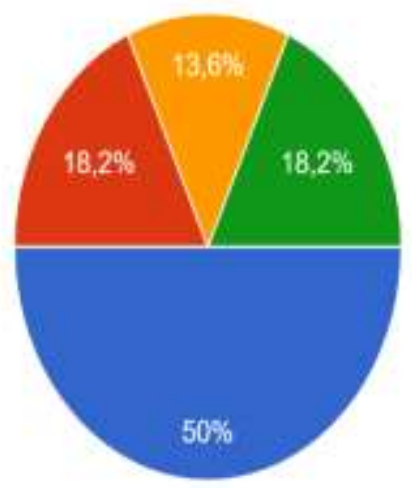

Microsoft Teams

Google Classroom

Moodle

Other:

Figure 20: Educational Platform used during Distance Teaching

Apparently, it seems that the majority of my respondents have used Microsoft Teams, $18,2 \%$ have had access to Google Classroom and the same percentage of respondents have used other educational platforms that have not been stated above while $13,6 \%$ have utilized Moodle.

One of them illustrates the following citation:

"I have had access to various educational platforms, such as Microsoft Teams, Moodle, Google Meet. In addition to this, I have also created Whatsapp groups with my students in order to reach them whenever I encounter WIFI connection issues" 


\section{In addition to the educational platform used, what tool did you use to make the videoconferences?}

\section{2\&nbsp;réponses}

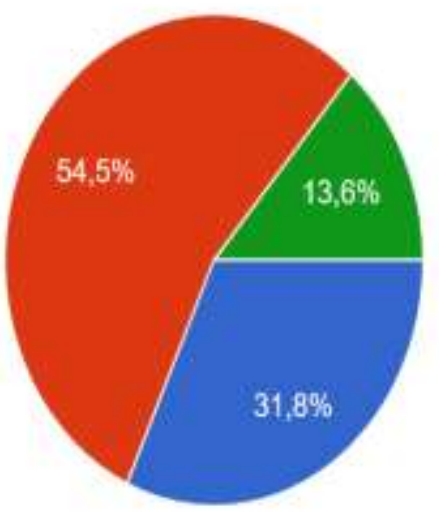

Zoom

Meet

Skype

Other :

Figure 21: Video Conferences Tools

$54,5 \%$ claim that they have useMeet to make their video conferences. $31,8 \%$ have had access to Zoom, and $13,6 \%$ have used other tools apart from the above-mentioned alternatives.

Based on your experience, what are the strengths of the educational platform?

\section{8 nbsp,réponses}

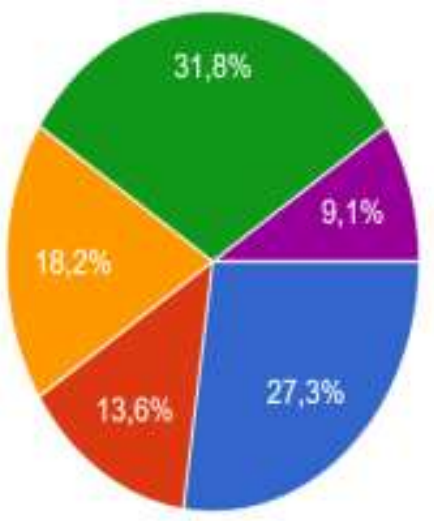

Collaboration

Synchronous Communication (Chat)

Asynchronous communication (Forum, Messaging)

Integrated Video Conferencing

Ongoing availability of courses

Figure 22: Educational Platform Strengths

$31,8 \%$ of my respondents had opted for integrated video conferencing as their major strength, $27,3 \%$ for collaboration, $18,2 \%$ for asynchronous communication, such as forum and messaging, 13,6\% for synchronous communication, such as chatting, and $9,1 \%$ for an ongoing availability of courses. 
Based on your experience, what are the strengths of the platform used?

22\&nbspréponses

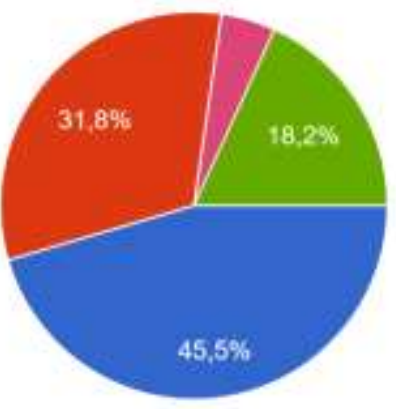

Usability

Ease of use

Speed

Compatibility

Documentation

Availability of user tutorials

Maintenance and updating

Security and stability

Figure 23: Platform Used Strengths

The majority states that the major strengths of the used platform are its usability while $31,8 \%$ opts for its ease of use. Besides, $18,2 \%$ illustrate that its strength lies in its security and stability, and 4,5 for its maintenance and updating

For you, how did the platform used contribute to the continuation of your teaching? 228nbspréponses

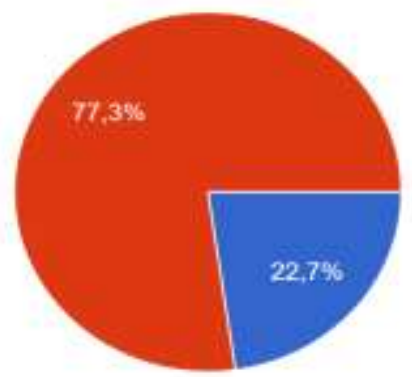

1- No contribution

2- Very significant contribution

Figure 24: Platform Contribution to Distance Teaching Continuity

$77,3 \%$ of respondents clarify that the platform has significantly contributed to their teaching while $22,7 \%$ disagree

Will you continue to use this platform proposed by your institution after the period of confinement?

228 nbspréponses

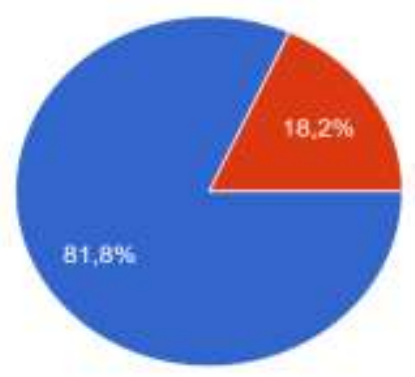

Yes

No

Figure 25: The Use of the Institution Platform after the Confinement Period 
Most of my respondents confirm that they will be using the institution platform after the confinement period; whereas, $18,2 \%$ will not use it all

One of them says:

"I believe that the face-to-face courses are more effective than the online one, but still if we use them both, the learning and the teaching processes will be more effective"

\section{Discussion}

As far as respondents' findings are concerned, they can be classified into three categories namely, the challenges of remote teaching continuity, self-organization for remote teaching, and the evaluation of the used teaching flatforms. For the first which tackles the challenges of remote teaching continuity, most respondents claim that they have never been introduced to distance teaching before, a fact which is quite challenging for them at the beginning of their distance teaching. Most of them are anxious about the way they are going to teach since they are accustomed to the traditional way and most of them confirm that they are not used to technology. Concerning the used means during distance teaching, the majority illustrate that they have taught through educational platforms, such as Microsoft Teams, Google Classroom, and Moodle, in addition to their emails and social media applications, such as Whatsapp, Skype, and Zoom. Also, almost all respondents have delivered online courses during the confinement period despite the fact they are not good at using computer applications or smartphones and they lack the necessary equipment for distance teaching. Thus, they are not satisfied with distance teaching at all.

As for respondents' self-organization for distance teaching, they claim that they may spend more than three hours per day in their distance teaching process. They believe that distance teaching is very exhausting and it is incomparable with in-person teaching. For the institution accompaniment during distance teaching, most of them illustrate that they do not need accompaniment while a minority of them have been supported by the institutions with which they are affiliated to. Concerning their self-organization during the activities of distance teaching, the majority clarifies that they have organized space at home, mainly an office of their own, in order to teach at ease. They all opt for the laptop as their major online teaching support since it is practical and it facilitates the distance teaching process to a great extent. In addition to this, most of my respondents confirm that they have encountered issues in distance teaching because of internet connections.

For the evaluation of the used teaching platforms, it appears that some educational platforms have been used by private institutions and others by public ones. For example, Microsoft Teams are mostly used by private institutions and it is a quite expensive platform; whereas, Moodle is used by the public ones, in addition to other platforms that can be accessed by teachers and students, such as Zoom and Google Meet, which are suitable as video conferencing tools. Most of them illustrate that the strengths of the educational platform are related to the integrated video conferences in addition to the fact that it paves the way for collaboration, asynchronous communication, such as forum and messaging, synchronous communication, such as chatting, and for the ongoing availability of courses as well. According to respondents, the used platforms can easily be used, secure and stable as well.

\section{Conclusion}

It can be concluded from the findings that distance teaching is tremendously challenging. Most university professors have encountered hard times during it because they are not used to it. They believe that is very exhausting and it is incomparable with in-person teaching. For the used means during distance teaching, most of them stated that they have taught through educational platforms, such as Microsoft Teams, Google Classroom, and Moodle, in addition to their emails and social media applications, such as Whatsapp, Skype, and Zoom.

Moreover, concerning their self-organization during distance teaching, they maintain that they have organized a space a home that is solely dedicated to distance teaching, which is their own office. They claim that they might spend more than three hours a day in their distance teaching, a fact which is tiring. Some of them state that they have been having been assisted by their institution in order to carry out the distance teaching process, while others have had no support apart from themselves. They all opt for the laptop as their major online teaching support since it is practical and it facilitates the distance teaching process to a great extent.

For the evaluation of the used teaching platforms, the main educational platforms used during the lockdown are various namely; Microsoft Teams, Google Meet, Moodle, and Zoom. They believe that their strengths are associated with their ease of use, they facilitate communication and pave the way for collaboration in addition to their security and stability as well.

\section{Acknowledgement}

I would like to thank my dear colleagues for their pertinent feedback and for devoting their time to filling in the questionnaire designed for the accomplishment of the study since this research paper could not have been achieved without their support. 


\section{References}

[1] Compton, L. K. (2009). Preparing language teachers to teach language online: a look at skills, roles, and responsibilities. Computer Assisted Language Learning, 22(1), 73-99.

[2] Hanover research (2011). Distance education models and best practices. 1101 Pennsylvania Ave. NW, Suite 600 Washington, DC 20004 P 202.756.2971 F 866.808.6585 www.hanoverresearch.com.

[3] Mehrotra, C., Hollister, C. D., \& McGahey, L. (2001). Distance learning: Principles for effective design, delivery, and evaluation. Sage Publications.

[4] Stanley, G. (2019). Introduction to remote language teaching. Innovations in education Remote teaching, 8.

[5] Whyte, S., \& Gijsen, L. (2016, April). Telecollaboration in secondary EFL: a blended teacher education course. In New directions in telecollaborative research and practice: selected papers from the second conference on telecollaboration in higher education 163-170. Research-publishing. net. 